\title{
Humanities
}

\section{Competence and compassion: A history of the Halifax Infirmary}

Mike Wong MD

Department of Anesthesiology, Pain Management \& Perioperative Medicine, Dalhousie University, QEll Health Sciences Centre, Halifax, NS, Canada

$\mathrm{P}$ art of the Queen Elizabeth II Health Sciences Centre, the Halifax Infirmary serves as a major tertiary care hospital for Nova Scotia and the other Atlantic provinces. It is the main Emergency Department for the city of Halifax and the only adult Level I Trauma Centre in Nova Scotia. Home to specialized services, including neurosurgery and cardiovascular sciences, the hospital also plays an instrumental role in Atlantic Canadian medical education as a teaching hospital for the Dalhousie University Faculty of Medicine as well as other health professions. A center of excellence for health research, the Halifax Infirmary boasts the expertise of numerous nationally- and internationallyrecognized investigators.

This article summarizes the history of the Halifax Infirmary, beginning with its conception under the auspices of the Sisters of Charity of Saint Vincent de Paul. Although the administration of the hospital - along with its physical location - has changed significantly after over a century of caring, the Halifax Infirmary has maintained a prominent role in alleviating suffering and infirmity beyond the borders of its local community.

\section{Genesis}

As an institution founded by the Sisters of Charity, a history of the Halifax Infirmary would be incomplete without describing this religious order's early work in Halifax. Originating in Maryland and New York, the Sisters of Charity were established in Halifax in 1849 through the Roman Catholic church by the Most Reverend William Walsh who also became the first Catholic Archbishop of Halifax. ${ }^{1}$ At first, the Halifax Sisters of Charity were solely concerned with teaching in local Catholic schools and looking after orphaned children. However in 1866, the Sisters were called upon when the ship England made landfall bearing hundreds of cholera-stricken Irish immigrants. ${ }^{2}$ These passengers were quarantined on McNabs Island and a makeshift field hospital was set up with the Sisters of Charity providing shelter and nursing the afflicted. Many perished, including the city health officer, and were buried in common graves on the island. However, the outbreak eventually relented.

Some Sisters involved in the McNabs Island outbreak later played a role in the order's next foray into nursing. Chief among them was Sister Mary Vincent, who would become the first administrator of the Halifax Infirmary. ${ }^{1}$ Early in 1886, the Sisters acquired the old Waverley Hotel, a former property of prominent Haligonian Judge Samson Blowers. This wooden building on the corner of Barrington Street and Blowers Street became the Home for Aged Women. ${ }^{3}$ After a few months in operation, a group of local physicians requested that the space be used for the provision of medical care, since there were few hospitals in Nova Scotia and a great need. During one instance in March 1887, a woman developed a condition requiring travel to Boston for surgery. Her physician persuaded the sisters to convert one of the Home's common rooms into a surgical suite, where the patient underwent her operation. She then enjoyed a full and expeditious recovery at the Home., ${ }^{1,2}$

From the spring of 1887 onwards, the Home for Aged Women increasingly provided care for patients with a variety of medical and surgical conditions. The building was renamed the Victoria Infirmary, in commemoration of Queen Victoria's Jubilee; however, it was rechristened the Halifax Infirmary to avoid confusion when the Provincial Hospital in Halifax was similarly renamed the Victoria General Hospital. Among the inaugural 6-member medical staff of the hospital were two surgeons and an eye and ear specialist. Patients were charged a rate of $\$ 5$ - 8 per week of admission, while the elderly women of the Home continued to live there for $\$ 100$ per year. ${ }^{2,3}$ Though at times burdened by financial challenges, the little hospital gained a reputation for its service, hospitality, and professionalism. The hospital admitted a total of 64 patients in the year 1890 alone. ${ }^{4}$ With increasing demand for its services, it quickly became apparent that larger facilities would be required. In 1903, a brick extension to the hospital opened its doors, and in that year 198 patients were treated (Figure 1). ${ }^{1,5}$

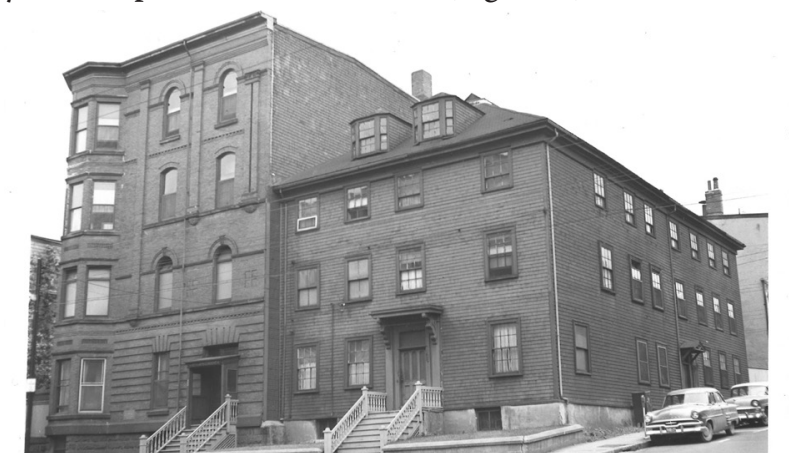

Figure 1. The corner of Barrington Street and Blowers St. On the right is Judge Blowers' house, the original Halifax Infirmary. The 1903 brick expansion is on the left. Photograph by Maurice Slaunwhite. Undated. 
As time went on, the hospital steadily expanded its scope of services. Its clinical experience inspired the founding of the Halifax Infirmary School for Nurses in 1908, which graduated its first cohort of students in 1911. With many poor and needy patients presenting for care, the Ladies' Aid Society of the Halifax Infirmary was established in 1910 to ensure patients would not be turned away for lack of funds; this would later be become the Halifax Infirmary Ladies' Auxiliary in 1949. ${ }^{6}$

During the Great War, a large number of Commonwealth sailors were cared for in the Infirmary, resulting in a special citation from King George $\mathrm{V}$ for this meritorious work. In December 1917, after the ships Imo and Mont-Blanc collided, some victims of the calamitous Halifax Explosion were treated in the Infirmary, which also hosted American physicians and nurses volunteering in the relief effort. ${ }^{1}$

The hospital entered the era of clinical radiology in 1922, with the acquisition of a state-of-the-art Victor X-ray machine. ${ }^{5}$ The next year, the Halifax Infirmary gained accreditation with the American College of Surgeons. ${ }^{6}$ From 1926 until 1933, the Sisters of Charity also administered a secondary branch of the Halifax Infirmary on the corner of Coburg Road and Edward Street. ${ }^{1,6}$ This site focused on maternal and neonatal care, offering 30 beds as well as its own operating theatre. ${ }^{3}$

Bustling with activity, the Halifax Infirmary had clearly come a long way since its humble beginnings. In 1928, the Infirmary admitted over 1500 patients and carried out 678 operations, with 620 of these performed under general anesthetic. ${ }^{7}$ Again in response to growing demand for health care in the city, the Sisters of Charity sought a suitable site to build a brand-new Halifax Infirmary hospital. In March 1929, the Sisters of Charity announced that an ideal, central location was secured on the east side of Queen Street, between Morris Street and Dundonald Street. Dundonald Street would later be closed off to make way for expansion of the Halifax Infirmary and nurses' residence in the 1960s.

\section{The Queen Street Halifax Infirmary}

The Queen Street site opened its doors on January 9, 1933, after which the original Barrington Street location became St. Mary's Convent., ${ }^{2,9}$ With 228 beds and a 60-bassinet nursery, the "New" Halifax Infirmary must have appeared expansive and splendid indeed. The 1936 Catholic Diocesan Directory heaped praise on the amenities of the well-equipped hospital, its expanded and ornate chapel, and the considerable efforts to make the hospital truly hospitable for patients, families, and staff. ${ }^{10}$ Lauded by the Directory as "a lasting memorial of what Halifax labor can accomplish when given full opportunity," the edifice's magnificence was perhaps best conveyed by this detailed report of its majestic main entrance that greeted visitors as they entered:

"...two magnificent solid bronze doors into a spacious vestibule and entrance hall, lined from floor to vaulted ceiling with Saint Genevieve marble in the beautiful color tones of grey, fawns and yellow, with inlaid gold tracery and base of black and gold. The floor is Tennessee marble and the hand railing that separates the entrance steps is a replica of the one in the Milan Cathedral."10

During its first year, the Queen Street Halifax Infirmary treated 2298 patients. ${ }^{3}$ Increasing demand for services within the Metro area and the province at large ensured the Infirmary remained constantly busy (Figure 2). During the Second World War, Infirmary staff also diligently attended to the needs of Merchant Marine and Navy personnel that swelled the population of Halifax. ${ }^{5}$ A special Marine Ward was established during these years. To acknowledge the distinguished care provided to the Merchant Marine during wartime, King George VI invested the Infirmary with insignia of the Order of the British Empire. ${ }^{11}$

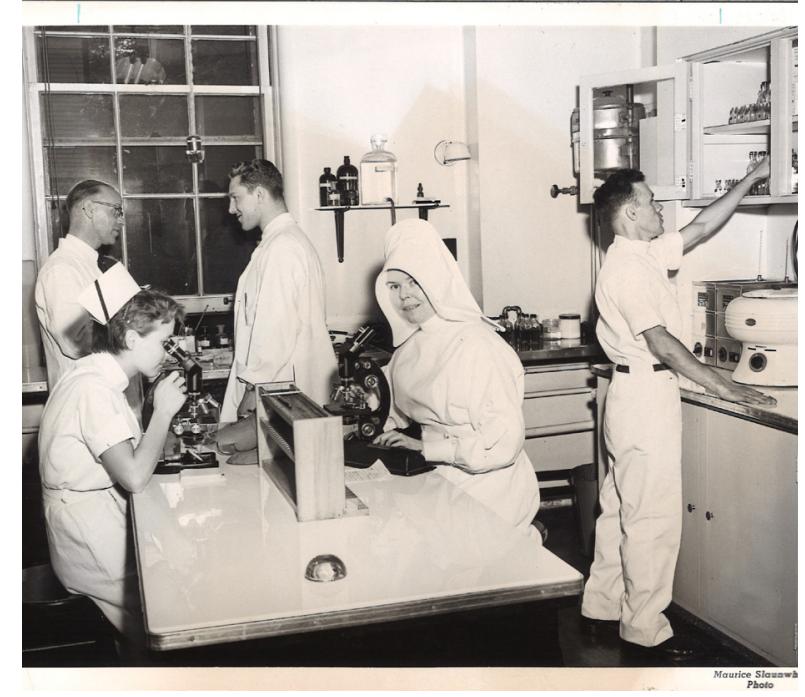

Figure 2. Sister Agnes Gerard Knowles in the laboratory. Photographer: Maurice Slaunwhite. Taken after 1934.

By 1961, an agreement was formalized with Dalhousie University to officially designate the Halifax Infirmary as a teaching hospital of their Faculty of Medicine. ${ }^{3}$ It would serve as an important training site for medical students, interns, and residents, though the bulk of clinical training was still carried out at the Victoria General Hospital, particularly in subspecialty services. A truly modern teaching hospital, the Infirmary made use of closed-circuit television allowing up to 200 students to observe operations in progress or view recordings of past surgeries. ${ }^{12}$

Throughout the 1960s, the Infirmary continued to expand its scope of services, opening a new north 


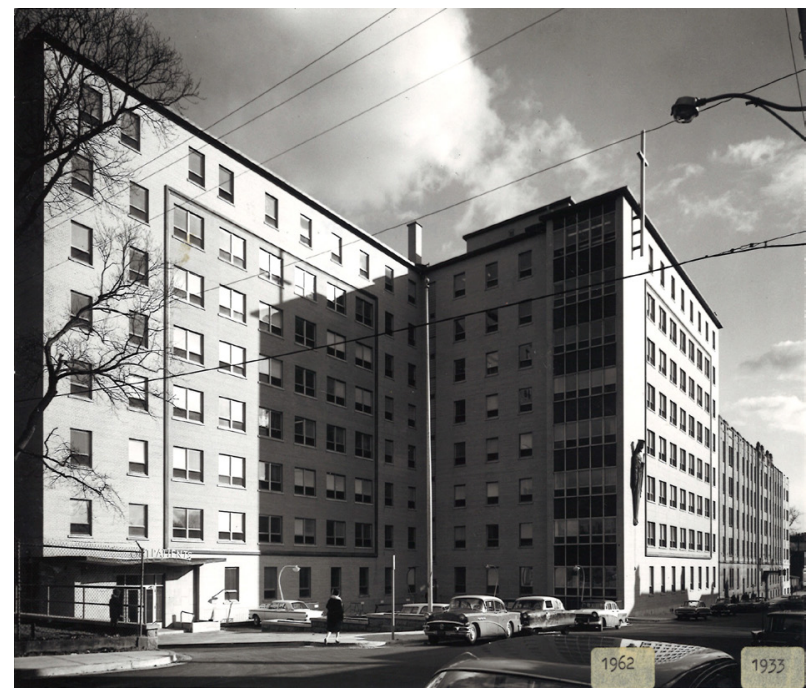

Figure 3. The Queen Street Halifax Infirmary. The prominent Jesus statue on the exterior wall may now be found at St. Vincent de Paul Parish in Cole Harbour. Photographer unknown. Taken sometime after 1961.

wing in 1962 to make way for the addition of Psychiatry, Otolaryngology, Pediatrics, Radiotherapy, Physical Medicine, and Social Services to the existing milieu of Anaesthesia, Diagnostic Radiology, Plastic and Reconstructive Surgery, Neurosurgery, Thoracics, Cardiovascular Surgery, and General Surgery.,13 A meticulously planned 12-bed Intensive Care Unit provided monitored care for high dependency and critically ill patients. ${ }^{14}$ In 1963, the Halifax Infirmary saw an impressive 14390 admissions, 3394 births, and 7230 operations (4 892 under general anesthetic); overall, this represented a ten-fold increase in volume over 30 years. $^{13}$ Figures 3 and 4 demonstrate the hospital during this period.

With much jubilation, November 6, 1967 heralded the opening of a new nurses' residence. Named after Sister Catherine Gerard, a longtime hospital administrator, Gerard Hall had a 300-bed capacity, a swimming pool, laboratory facilities, classrooms, and an auditorium-gymnasium accommodating 500 people. ${ }^{15,16}$ At the accompanying reception, guests and dignitaries were entertained by the harmonious stylings of the Halifax Infirmary Glee Club. During this period, the Halifax Infirmary was not only a place of work for its growing staff. As evidenced by its active Glee Club, the Infirmary fostered a vibrant sense of community, that was also vividly documented in the H.I. Lites (previously, Infirmary Quarterly) newsletter, advertising an ample social calendar, training opportunities, employment openings, public outreach events, personal milestones and religious feast days. ${ }^{17-20}$

\section{New management}

Unfortunately, the 1970s were a troubled time

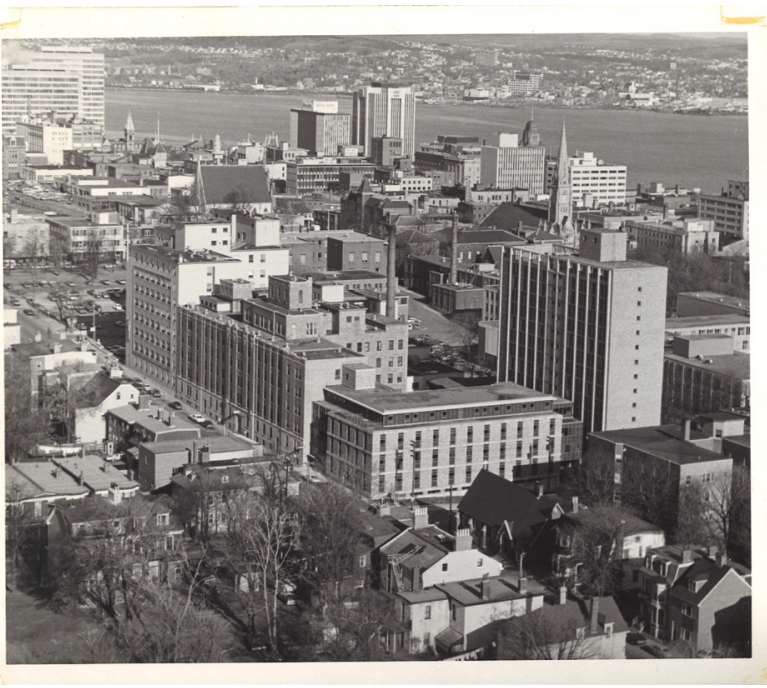

Figure 4. Aerial photograph of the Queen Street Halifax Infirmary. Gerard Hall still remains, as a Dalhousie University student residence. Photographer unknown. Mid-1970s.

for the Halifax Infirmary. Over the years, the hospital had obviously become a major referral center in the province; early into the decade there was increasing awareness of the escalating costs associated with this role. Under the watchful guidance of the Sisters of Charity, the Halifax Infirmary had weathered past fiscal shortfalls, but the organization was beginning to falter under strain of possible insolvency. Operating expenses were not entirely offset by payments from the Hospital Insurance Commission or municipal grants. A large capital debt and costs associated with serving as a teaching hospital also added to the financial pressures. ${ }^{21,22}$ Furthermore, restructuring of church administration following Vatican II reduced the capacity of the Sisters to manage the daily activities of the institution. Overall, this was an era marked by poor morale, with substantial concerns regarding equipment quality and maintaining high standards of patient care. ${ }^{23}$

On January 4, 1973, an announcement was made that administration of the hospital would be transferred to the provincial government. ${ }^{20,24}$ After 86 years, the Sisters of Charity ceased to own and operate the Halifax Infirmary. Yet in spite of initial uncertainty surrounding the administrative changes, that September Halifax Infirmary staff were able to decisively manage a significant influx of patients, after a mass resignation of nursing staff from the Victoria General Hospital and the Nova Scotia Hospital. ${ }^{25}$

With the opening of the Isaak Walton Killam Hospital for Children in 1971, the Halifax Infirmary shuttered its Pediatrics unit. A few years later, in 1976, Obstetrics would experience the same fate, leaving the Salvation Army-administered Grace Maternity Hospital to assume pre-eminence for maternal care in 
Halifax. ${ }^{26}$ Fortunately, this decade did not exclusively see the diminution of services from the Infirmary, as Otolaryngology and Ophthalmology were moved from the Victoria General and Camp Hill Hospitals to be consolidated at the Halifax Infirmary in 1979.27,28 Indeed during this decade, demographic changes and financial challenges contributed to numerous calls for further amalgamation of the Halifax hospitals, and elimination of redundancies. ${ }^{29-31}$ In 1980, there were announcements for a new health complex to replace the Camp Hill, Grace Maternity, and Halifax Infirmary hospitals. This gargantuan, $\$ 81.5$ million Camp Hill Complex on Summer Street was planned for occupancy by 1985. A sod-turning ceremony took place on November 16, 1981. ${ }^{32,33}$

In reality, construction of a hospital complex would not be underway for over a decade, and plans for the project would change substantially before its completion. In 1985, Premier John Buchanan officially re-announced intentions to build a new hospital at the Camp Hill site, with a 535-bed capacity and a connection to the neighbouring Veterans' Memorial Building and Abbie J. Lane Hospital. At this time, the budget for construction was revised to $\$ 94.6$ million. At the request of the Sisters of Charity, the future hospital would retain the name of Halifax Infirmary. ${ }^{34-}$ ${ }^{36}$ This second wave of enthusiasm was dampened by the province's sluggish financial outlook, while a $\$ 3.8$ million Royal Commission on Healthcare cast further doubt on the future of the putative hospital complex. Contrary to the provincial government's intentions, the 1989 Royal Commission called for a cessation of capital construction on new hospitals and instead called for a shift in emphasis from acute care to health promotion, disease prevention, and the expansion of community-based clinics. ${ }^{37-42}$ After some deliberation, in 1991 Health Minister George Moody reaffirmed the province's intentions to construct the new Halifax Infirmary regardless of these recommendations. ${ }^{38}$

During these unsettled years, the Halifax Infirmary continued to tirelessly serve the needs of Nova Scotians. In 1985, the Infirmary had 12461 admissions, 12294 operations, and 26210 Emergency Department visits. ${ }^{36}$ The services offered at the hospital also evolved during the 1980s, with the Halifax Infirmary becoming home to an arthroscopic surgical unit (1985), the Nova Scotia Diabetes Centre (1986), the division of Endocrinology and Metabolism (1986), and Nova Scotia's first dedicated Palliative Care unit (1988). ${ }^{36,43}$ In anticipation of a merger with the Camp Hill and Abbie J. Lane hospitals, the 24-bed Psychiatry unit was phased out after 1987. ${ }^{44}$ The auxiliary remained active in supporting the Infirmary, though ongoing shortfalls in government funding spurred the creation of the Halifax Infirmary Foundation. ${ }^{36}$

\section{Introducing the Queen Elizabeth II Health Sciences Centre}

As preparations for the new Halifax Infirmary progressed, announcements were made for increasingly extensive amalgamation of hospital services in Halifax. Once envisioned as a full service community hospital, administration of the as-yet unfinished Halifax Infirmary would be further merged with the Victoria General Hospital, the Nova Scotia Rehabilitation Centre, and the Nova Scotia Cancer and Research Centre. This multi-site, tertiary-care "megahospital" would be the first of its kind in Canada. ${ }^{45,46}$ This new mega-hospital was officially designated the Queen Elizabeth II Health Sciences Center (QEII), to coincide with the Queen's 3-day visit to Nova Scotia in 1994. The unexpected christening attracted criticism for lack of originality, and the government of the day was also accused of politicizing the Queen's visit, but nonetheless the QEII was here to stay. ${ }^{47,48}$

More significant controversy ensued while bringing together around 6000 employees from the separate hospitals under the banner of the QEII.99-51 Previously represented by 3 different labour unions and governed by 14 collective agreements, many of these employees worked under significantly different pay scales requiring renegotiation under new collective agreements. ${ }^{52}$ Questions and concerns about hundreds of potential lay-offs regularly peppered the pages of Merger Memo, a newsletter for employees of the nascent QEII. Disparities between the previously separate hospitals were articulated by concerns that key QEII positions were preferentially staffed by employees of the Victoria General..$^{53}$ Thus, along with some excitement and eager anticipation, the early years of the QEII were clearly marked by high employee anxiety and low morale. In a statement Maura Davies, the QEII vice-president of planning and quality management, remarked:

"It takes a long time to establish a culture for a new organization and we don't expect to do that overnight. For many of our staff, they will be working in a new environment, they will be working with new colleagues, and that will be a major change and a major stress for a lot of them."49

When the new Halifax Infirmary was completed in 1996, the final cost of construction exceeded $\$ 130$ million, plus a dramatic last-minute $\$ 12$ million renovation where most of the extensive, newlyinstalled 6th floor laboratories were removed to instead consolidate laboratory services down the street at the Victoria General Hospital Mackenzie Building. The 6th floor space subsequently became home to cardiovascular sciences. ${ }^{54-56}$

By early 1997, the Summer Street Halifax Infirmary was ready for patients. The considerable task of 
transferring all inpatients from the Queen Street Infirmary to the new site was undertaken over the course of 3 weeks. 120 patients were moved between February 24 and 28, and the remaining 160 patients were transported uneventfully on March 1 . On March 1, the new Halifax Infirmary Emergency Department opened its doors for the first time as the only Emergency Department in metro Halifax, while the Victoria General and old Halifax Infirmary Emergency Departments closed permanently. ${ }^{49,51,57}$ Some clinics remained at the Queen Street location briefly after the move, until renovations at the Victoria General Hospital were completed. By the end of the year, the old Infirmary was left unoccupied. ${ }^{58}$

The fate of the defunct Queen Street property would stay undecided for a number of years. Despite negotiations dating back to the 1980s for the transfer of the property to the Technical University of Nova Scotia (TUNS), no firm arrangement had yet been made..$^{59}$ Talks continued with Dalhousie University after they had merged with TUNS, but an agreement on terms of the transfer was unfortunately elusive. All the while, Halifax developers and the Halifax library board also expressed interest in utilizing the 1.9-hectare site. ${ }^{60-62}$

The indeterminate future of the Queen Street Infirmary buildings became a political liability after revelations that the Nova Scotia provincial government had spent over $\$ 324000$ to ensure minimal maintenance of the derelict hospital between 1999 and $2002 .{ }^{63}$ Aside from some movie productions that shot on site up to 1999, the Queen Street Infirmary remained empty and unused, leading to occupation by squatters. ${ }^{64}$ During the early 2000s, it was the site of several raucous protests concerning homelessness and affordable housing in Halifax. ${ }^{65,66}$ For some in the community, the sorry state of the Queen Street Infirmary must have been disappointingly reminiscent of the fate of the old Barrington Street Infirmary building. In spite of avid interest for redevelopment in the 1980s, the historic Barrington Street location lay derelict during its final years and had similarly become inhabited by homeless people. ${ }^{60,67-69}$ Affectionately nicknamed "Hell's Hotel," the Barrington Street building met an ignoble end after some squatters accidentally set the structure ablaze, leading to its demolishment in December $1993 .{ }^{60,69,70}$

In 2004, Murray Demolition of Ontario was awarded a contract to tear down the Queen Street Infirmary, having carried out the demolition of the Cape Breton Sysco steel plant as well as the Toronto Princess Margaret hospital. ${ }^{71,72}$ An iconic statue of Jesus on the exterior wall of the hospital was spared from the scrapyard, as it was relocated to the Saint Vincent de Paul Parish in Cole Harbour shortly after the hospital closure. ${ }^{73}$ Additionally, religious artifacts and artwork in the hospital chapel had already been repatriated to the Sisters of Charity, and were saved from destruction. ${ }^{74}$
The last days of the Queen Street Infirmary were documented in a photo exhibition by Halifax artist Angela Carlsen (Figure 5). Capturing the dramatic deterioration of the building, the exhibition generated interest in the local community. However, many former staff from the once-magnificent Halifax Infirmary could not bear to see the decay of that colossal wreck. ${ }^{75,76}$ Demolition took place during 2005, and yielded a time capsule tucked behind the original cornerstone. Amid much fanfare, the time capsule revealed a variety of ephemera dating back to 1933: newspapers, coins, a list of hospital employees, and religious memorabilia. ${ }^{77}$

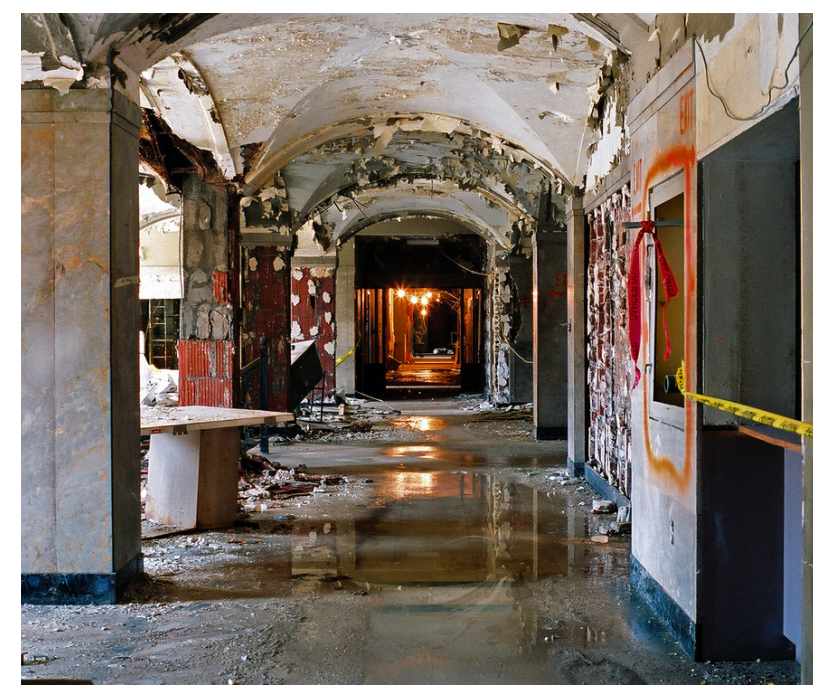

Figure 5. View from within the Queen Street lobby, prior to demolition. Photographer: Angela Carlsen. 2005.

\section{Opportunities and challenges ahead}

As time went on, many challenges faced during the QEII hospital amalgamation were eventually resolved. The new Summer Street Halifax Infirmary would emerge from the shadow of its predecessor, and develop a reputation and character all its own (Figure 6). As a busy tertiary care centre, the Halifax Infirmary provides specialized medical and surgical services for Nova Scotia and beyond. It also plays an instrumental role in medical education, for medical students, resident physicians, and other allied health trainees.

It is expected that, with aging demographics in the Atlantic Provinces and increasing burden of chronic disease, there will be ever-growing demands on the Halifax Infirmary. In 2012, 33259 patients were admitted within the Capital District Health Authority (including the Halifax Infirmary, Victoria General, Dartmouth General, and other sites).$^{78}$ In 2015, over 60 000 surgical procedures involving anesthesia care were carried out between the Victoria General and Halifax Infirmary sites. ${ }^{79}$ Annual Emergency Department visits now regularly exceed $700000^{80}$

During January 2009, patient overcrowding at the Halifax Infirmary Emergency Department resulted in 


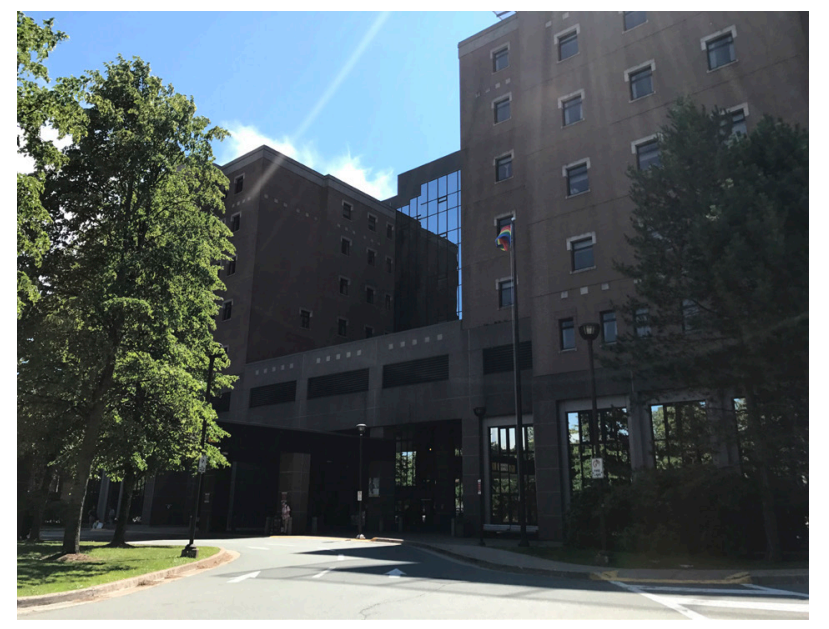

Figure 6. Summer Street entrance to the new Halifax Infirmary. Photographer: Mike Wong. 2017.

the drastic announcement of Code Orange, usually reserved for mass casualty events. ${ }^{80}$ Intended to alleviate the strain on Emergency Department resources, this action compelled in-patient units to hasten admission of Emergency Department patients. This practice would later be redeveloped into a new Code Census alert. Though the June 2009 opening of an extensive Emergency Department expansion was hoped to provide some relief for this overcrowding, the capacity of the Halifax Infirmary is still continually being tested, with 23 Code Census alerts in January 2017 alone. ${ }^{80-82}$

In light of recurrent flooding and general concerns about the aging infrastructure of the Victoria General Hospital, further change is afoot as some services at that site will be expected to gradually migrate to the Halifax Infirmary site. ${ }^{83,84}$ For instance, in 2015, a new dialysis unit was opened at the Infirmary. ${ }^{85}$ As part of a significant redevelopment plan over the next few years, the Halifax Infirmary will see a renewal of interventional radiology suites and an addition of new operating rooms. ${ }^{86,87}$ The 2007 closure of the Queen Elizabeth High School adjacent to the Halifax Infirmary also made available a sizeable plot of land for potential further development of the hospital. ${ }^{83,88,89}$ Currently this site is home to the Common Roots Urban Farm, a community garden that sells its produce on-site and also donates over 1000 pounds of vegetables for food bank donation each year. ${ }^{90,91}$ As plans for the Halifax Infirmary continue to evolve, it is still unclear exactly how this plot will be used in the future.

Certainly, the Halifax Infirmary has come a long way since its first operations were carried out in the parlour of the Home for Aged Women. Technological advances and sociopolitical changes have greatly changed the delivery of health care in Nova Scotia. The scope of the current Infirmary complex would likely have been inconceivable to its original founding Sisters. Yet, in spite of these changes, patients through the years have been able to count on the Halifax Infirmary's age-old virtues of competence and compassion, and this at least will be one constant as the institution moves everforward into an uncertain future.

\section{Acknowledgements}

Many thanks to the following for their assistance: to Dr. Jock Murray and Dr. Allan Marble for fostering an appreciation of local medical history and for editorial feedback; to Mary Flynn for her guidance navigating the Sisters of Charity archives, including their many historical photographs; and, to Angela Carlsen for her photography of the Queen Street site pre-demolition.

\section{References}

1. Power SM. The Sisters of Charity - Halifax. Toronto: Ryerson Press; 1956. 167-171.

2. Murphy AL. Early days of the Halifax Infirmary. Nova Scotia Medical Bulletin. 1934;13(4):175.

3. Macdonald N. The Halifax Infirmary....a special place.” The Mail-Star. 1986 Apr 28. Halifax Infirmary. Annual Report. 1890.

4. Halifax Infirmary. Annual Report. 1890.

5. Grogono B. Our Lady of All Souls. Nova Scotia Medical Bulletin. 1977;55:78.

6. Halifax Infirmary. Halifax Infirmary: 100 years of service. 1984.

7. Anonymous. Halifax Infirmary is carrying on great work. Evening Mail. Mar. 291929.

8. Anonymous. Part of street may yield to allow infirmary growth. The Mail-Star. Apr. 161958.

9. Anonymous. Sisters move into former infirmary. The Halifax Mail. Oct. 251933.

10. Archdiocese of Halifax. The Catholic Diocesan Directory of Nova Scotia. Kentville NS: Archdiocese of Halifax; 1936.

11. Anonymous. Infirmary treats 6,403 in seven months of ' 58 . The Mail-Star. Aug. 161958.

12. Anonymous. 200 can watch operations on TV. The Mail-Star. Jun. 231962.

13. Halifax Infirmary. Annual report. 1963.

14. Feindel J. The intensive care unit. Nova Scotia Medical Bulletin. 1968 Aug;47(5).

15. Anonymous. New infirmary nurses' residence officially opened. The Chronicle-Herald. Nov. 71967.

16. Anonymous. New infirmary nurses' residence officially opens today. The Mail-Star. Nov 6. 1967.

17. Anonymous. Infirmary Quarterly. Issue 10. Apr. 1951.

18. Anonymous. H.I. Lites. Vol. 3. 1969.

19. Anonymous. H.I. Lites. 1974.

20. Anonymous. H.I. Lites. 1973.

21. Anonymous. Infirmary aid is discussed. The Chronicle-Herald. Feb 3. 1971.

22. Anonymous. Financial situation "acute" at Infirmary. The Chronicle-Herald. Sep. 11970.

23. Thompson I. Financial state still "serious" despite grant. The Chronicle-Herald. Jan 12. 1972.

24. Golding P. Province takes over Halifax Infirmary. The ChronicleHerald. Jan. 251973.

25. Halifax Infirmary. Annual Report. 1973.

26. Hinds B. Infirmary to close 18 more beds. The Mail-Star. May 181976.

27. Miller P. Nova Scotia Eye Centre opened. The Mail-Star. 1979 Dec. 91976.

28. Halifax Infirmary. Annual Report. 1977.

29. Gray E. 4-hospital facility start urged. The Mail-Star. Apr. 11 1979.

30. Barnard E. New hospital gets green light. The Mail-Star. Sep. 141979. 
31. McMahon F. Costs could jeopardize complex. The ChronicleHerald. Apr. 161980.

32. Vibert J. $\$ 81.5$ million Halifax hospital complex could be ready for occupancy by 1985. The Chronicle-Herald. Mar. 111980.

33. Davies G. N.S. residents worry about lacking studies on hospital complex. The Globe and Mail. Mar. 291982.

34. Anonymous. New Grace, Infirmary hospitals for Halifax. The Daily News. Oct. 261985.

35. Smith L. Premier reaffirms pledge for new Infirmary hospital. The Mail-Star. Jan. 221985.

36. Halifax Infirmary. Annual Report. 1986.

37. Ware B. Delay urged in infirmary construction. The Daily News. Nov. 171991.

38. Tibbetts J. Infirmary contract awards said near. The ChronicleHerald. Nov. 191991.

39. Fendick R. New infirmary project going ahead. The Daily News. Oct. 181991.

40. Tibbetts J. The Infirmary health care puzzle. The Mail-Star. Nov. 41992.

41. Ward B. Infirmary construction delayed. The Chronicle-Herald. May 311990.

42. Nova Scotia Royal Commission on Health Care. The report of the Nova Scotia Royal Commission on Health Care. 1989.

43. Robinson P. Buchanan opens first palliative care unit. The Chronicle-Herald. Apr. 41989.

44. Jones R. Infirmary closing psychiatric ward. The ChronicleHerald. Apr. 41989.

45. Nicoll C. Halifax mega-hospital in works. The Daily News. Jul. 91994.

46. Cox K. Giant hospital merger begins in Halifax. The Globe and Mail. Jul. 61996.

47. McLaughlin P. Hospital's royal name blasted. The Daily News. Aug. 141994.

48. Myrden J. Hospital officially christened as Queen ends visit. The Chronicle-Herald. Aug. 161994.

49. MacKinlay S. Two kinds of hospital mergers. The Daily News. Jan. 21997.

50. Cox K. N.S. hospital merger nears completion. The Globe and Mail. Feb. 171997.

51. MacKinlay S. All here safe and sound. The Daily News. Mar. 2 1997.

52. MacKinlay S. Wage gaps irk QEII union. The Daily News. Feb. 61997.

53. Anonymous. Merger Memo. 1996.

54. LeBlanc S. New Infirmary gradually opening. The ChronicleHerald. Jun. 81996.

55. MacKinlay S, Rodenhiser D. Infirmary fix hits $\$ 12 \mathrm{~m}$. The Daily News. Nov. 11996.

56. LeBlanc S. Infirmary officially opens. The Chronicle-Herald. Nov. 161996.

57. Martin R. Keeping calm on moving day. The Daily News. Mar 31997.

58. LeBlanc S. Pack up all your cares and woes. The Mail-Star. Jun. 281996.

59. MacNeil J. Infirmary takeover plans "still in the air." The Mail-Star. Apr. 281987.

60. Gillis J. Old hospital suffering from neglect. The ChronicleHerald. Aug. 262002.

61. Erskine B. No infirmary plans yet. The Chronicle-Herald. Jul. 132005.

62. Flinn B. Demolition derby. The Daily News. Dec. 32003.

63. Lambie C. Empty hospital costs province tens of thousands a year. The Daily News. Nov. 282002.
64. Anonymous. Emergency still. The Chronicle-Herald. Feb. 24 2004.

65. Dorey B. Homeless standoff. The Chronicle-Herald. Oct. 27 2002.

66. Ozano N. Plan to occupy abandoned building on hold. The Daily News. Nov. 72004.

67. Power B. Developers want the old infirmary. The Mail-Star. Apr. 121985.

68. Sword P. Historic building's fate undecided. The Mail-Star. Jan. 81993.

69. Rodenhiser D. Wreckers to finish off fire-struck building. The Daily News. Dec. 181993.

70. Ware B. Homeless protest as annex torn down. The Daily News. Dec. 191993.

71. Anonymous. Firm to demolish old infirmary. The Daily News. Dec. 142004.

72. Anonymous. Old infirmary coming down. The Daily News.

73. MacDonald J-A. Jesus statue, crosses leave old Infirmary, too. The Daily News. Jul. 251997.

74. Farmer SI. File in archives. 1997.

75. Lisk D. Last round at Halifax Infirmary. The Daily News. May 262006.

76. Lisk D. Images of textured decay and memories. The Daily News. Oct. 152007.

77. Taplin J. Time capsule gives glimpse of 1933 . The Daily News. Nov. 182005.

78. Capital Health. Capital Health 2012-13 Annual Report. 2013.

79. Department of Anesthesia, Pain Management and Perioperative Medicine. Annual Report 2015-2016. 2016.

80. NSGEU. Code Critical. Mar. 2017.

81. Halifax trauma centre opens in June. The Times \& Transcript. May 212009

82. Anonymous. "New Halifax emergency centre to open in June." <http://www.cbc.ca/news/canada/nova-scotia/new-halifaxemergency-centre-to-open-in-june-1.840807> (2009)

83. Levangie, B. "Innovative care, flexible facilities." QEII Times. $<$ http://thechronicleherald.ca/qe2times/in-focus/1200910innovative-care-flexible-facilities $>$ (2013)

84. "Relocation of VG hospital services to begin late 2016" < http:// globalnews.ca/news/2653073/relocation-of-vg-hospitalservices-to-begin-in-2016-for-start-of-decommissionprocess/> (2016)

85. Wong, J. "New dialysis unit at Halifax Infirmary can meet demand - for now." Global News. <http://globalnews.ca/ news/1902713/new-dialysis-unit-at-halifax-infirmary-canmeet-demand-for-now/> (2015)

86. Anonymous. Halifax Infirmary and Hants Community Hospital progressing. The Chronicle-Herald. Mar. 2017.

87. "QEII Redevelopment Timeline." <https://qe2redevelopment. novascotia.ca/timeline>

88. Massinon S. QEII covets QEH. The Daily News. Nov. 272007.

89. Teubner S. Pave QEH and put up a parking lot? Weekly News. Apr. 42008

90. Cousins B. Refugee farmer puts down Halifax roots. The Chronicle-Herald. Jun. 72017.

91. "Halifax community gardens give urbanites the chance to grow." <http://www.cbc.ca/news/canada/nova-scotia/ halifax-community-gardens-give-urbanites-the-chance-togrow-1.2653227> (24 May 2014).

92. Anonymous. Coat of arms of the Halifax Infirmary, Halifax, Nova Scotia. Undated. 